Yumi Nishio • Emiko Noguchi • Seiko Ito • Eiko Ichikawa

Yoshihiro Umebayashi · Fujio Otsuka • Tadao Arinami

\title{
Mutation and association analysis of the interferon regulatory factor 2 gene (IRF2) with atopic dermatitis
}

Received: July 31, 2001 / Accepted: August 21, 2001

\begin{abstract}
Interferon regulatory factor 2 (IRF-2) is a member of a family of transcriptional factors involved in the modulation of cellular responses to interferons (IFNs) and viral infection as well as in the regulation of cell growth and transformation. Irf2 knockout mice show T helper 1 (Th1) cell development defect and spontaneous development of an inflammatory skin disease. To determine if there are any mutations in IRF2 associated with development of atopic dermatitis (AD), we screened for mutations in the $5^{\prime}$ flanking and coding regions of IRF2 in AD patients and control subjects by single-strand conformational polymorphism (SSCP) analysis. We found three mutations in the promoter region $([-829 \mathrm{C}>\mathrm{T},-830 \mathrm{C}>\mathrm{T}],-684 \mathrm{C}>\mathrm{T}$, and $-467 \mathrm{G}>\mathrm{A})$, one silent mutation in exon $9(921 \mathrm{G}>\mathrm{A})$, and a 10-bp deletion in the $3^{\prime}$ untranslated region (1739[ATCCC] $8>6$ ). Among them, the $-467 \mathrm{G}$ allele and the haplotype of the $-467 \mathrm{G}, 921 \mathrm{~A}$, and 1739 (ATCCC) 8 alleles were transmitted preferentially to AD-affected children $(P=0.02$ and $P=0.007$, respectively). Our data suggest that IRF-2 plays some role in the development of $\mathrm{AD}$ in the Japanese population.
\end{abstract}

Key words Atopic dermatitis $\cdot I R F 2 \cdot$ Polymorphism $\cdot$ Japanese population $\cdot$ Transmission disequilibrium test

Y. Nishio $\cdot$ E. Noguchi $\cdot$ S. Ito $\cdot$ T. Arinami $(\square)$

Department of Medical Genetics, Institute of Basic Medical

Sciences, University of Tsukuba, 1-1-1 Tennoudai, Tsukuba 305-

8575, Japan

Tel. +81-298-53-3352; Fax +81-298-53-3333

e-mail: tarinami@md.tsukuba.ac.jp

Y. Nishio $\cdot$ E. Ichikawa $\cdot$ F. Otsuka

Department of Dermatology, Institute of Clinical Medicine,

University of Tsukuba, Tsukuba, Japan

Y. Umebayashi

Department of Dermatology, Hitachi General Hospital, Ibaraki,

Japan

\section{Introduction}

Atopic dermatitis (AD) features an intensely pruritic rash with a charactristic morphology and distribution. It affects $10 \%-20 \%$ of children in developed countries and shows strong familial aggregation (Larsen et al. 1986). Eighty percent of AD cases show elevated total serum IgE levels (Juhlin et al. 1969), and atopic mechanisms dominate current understanding of the pathogenesis of this disease (Bos 2000).

Interferon regulatory factors (IRFs) comprise a family of transcriptional factors that includes IRF-1, IRF-2, ICSBP, p48, IRF-3, IRF-4, IRF-7, and vIRFs. They are involved in modulation of cellular responses to interferons (IFNs) and to viral infection and in the regulation of cell growth and transformation. IRF-2 was originally described as an antagonist of IRF-1-mediated transcriptional regulation of IFN-inducible genes (Harada et al. 1989). IRF-1 deficiency results in increased production of $\mathrm{T}$ helper (Th) 2-related cytokines and a compensatory decrease in the expression of naive cell- and Th1-related cytokines (McElligott et al. 1997). Irf2 knockout mice show a defect in Th1 cell development, impairment of natural killer cells (Lohoff et al. 2000), and spontaneous development of an inflammatory skin disease involving CD8 $+\mathrm{T}$ cells (Hida et al. 2000). These observations suggest that IRF2 might be involved in the pathogenesis of AD.

We screened for mutations in the $5^{\prime}$ flanking and coding regions of $I R F 2$ on chromosome $4 \mathrm{q} 35$ in AD patients. We found five novel variants in $I R F 2$ and conducted a transmission disequilibrium test (TDT) in families identified through patients with AD.

\section{Subjects and methods}

Subjects

Probands of the families studied were patients with AD who visited the Department of Dermatology or Pediatric 
Allergy Clinic of the University Hospital of Tsukuba, Japan. A full verbal and written explanation of the study was given to all family members interviewed, and 49 families (180 members, including children with atopic asthma) gave informed consent and participated in the study. The mean age of the probands and their siblings was 13 years (range, 1 to 36 years), and the mean age of the parents was 42 years (range, 28 to 72 years). Each family member was questioned regarding allergic symptoms, and each underwent physical examination by a participating dermatologist. $\mathrm{AD}$ was diagnosed in subjects according to the criteria of Hanifin and Rajka (1980).

\section{Screening for mutations}

Genomic DNA was isolated from peripheral blood leukocytes collected in ethylenediaminetetraacetate by the standard phenol/chloroform extraction method. The nine exons and the promoter region of IRF2 were amplified from genomic DNA of 24 subjects with AD and 24 control subjects. Subjects with AD were selected randomly for the mutation study from among the AD probands described above.

All exons and exon-intron junctions and the $5^{\prime}$ flanking region $1655 \mathrm{bp}$ upstream of the translation initiation site were amplified by polymerase chain reaction (PCR). Primers for exons were designed according to the published sequence of IRF2 (GenBank Accession Numbers L24442, NM_002199) (Cha and Deisseroth 1994; Harada et al. 1989). Single-strand conformational polymorphism (SSCP) analysis was done for all PCR products (each exon and the promoter region for each individual). PCR products with variant SSCP patterns were subjected to sequence analysis.

\section{Genotyping}

To genotype the polymorphisms, each region of interest was amplified by PCR with a primer pair as shown in Table 1 . The $[-829 \mathrm{C} / \mathrm{T},-830 \mathrm{C} / \mathrm{T}]$ (the first nucleotide of NM_002199 was denoted +1), $-684 \mathrm{C} / \mathrm{T},-467 \mathrm{G} / \mathrm{A}$, and 921G/A mutations were identified by the loss of Fnu4HI, gain of MseI, gain of NlaIII, and loss of Fnu4HI restric- tion sites, respectively. Digested PCR fragments and PCR products for the 1739(ATCCC)6-8 polymorphism were subjected to agarose gel electrophoresis and visualized by ethidium bromide staining and ultraviolet transillumination.

\section{Statistical analysis}

Deviation from Hardy-Weinberg expectancy was examined by $\chi$-squared test. An allelic transmission disequilibrium test (TDT) was performed via the GENEHUNTER version 2 program (http://www-genome.wi.mit.edu/ftp/distribution/ software/genehunter/). $P$ values less than 0.05 were considered significant.

\section{Results and discussion}

We identified three mutations in the promoter region $([-829 \mathrm{C}>\mathrm{T},-830 \mathrm{C}>\mathrm{T}],-684 \mathrm{C}>\mathrm{T}$, and $-467 \mathrm{G}>\mathrm{A})$, one silent mutation in exon 9 (921G $>A, G 248 G)$, and a 1739(ATCCC) $8>6$ in the $3^{\prime}$ untranslated region (UTR) (Fig. 1). Among these five polymorphisms, $[-830 \mathrm{C} / \mathrm{T}$, $-829 \mathrm{C} / \mathrm{T}]$ and $-684 \mathrm{C} / \mathrm{T}$ were rare, appearing in only 1 and 6 of 92 subjects, respectively.

The 1739(ATCCC)6-8 polymorphism was in complete linkage disequilibrium with the 921G/A polymorphism ( $\left.n=168, D=0.0428, D^{\prime}=1.0, P<0.0001\right)$, but no significant linkage disequilibrium was observed between the $-467 \mathrm{G} / \mathrm{A}$ and $921 \mathrm{G} / \mathrm{A}$ polymorphisms $(n=160, D=$ $0.0147, D^{\prime}=0.176, P=0.3$ ).

The genotype frequencies of the $-467 \mathrm{G} / \mathrm{A}$ and $921 \mathrm{G} / \mathrm{A}$ and 1739 (ATCCC)6-8 polymorphisms in the parents did not deviate from expected Hardy-Weinberg equilibrium frequencies $(P>0.05)$. According to TDT analysis, the $-467 \mathrm{G}$ allele was transmitted preferentially to AD-affected children $(P=0.02$, Table 2$)$, but statistical significance was not reached after correction for multiple comparison $(P c=$ 0.06). Neither allele of the $921 \mathrm{G} / \mathrm{A}$ or 1739 (ATCCC) $6-8$ polymorphisms was transmitted preferentially to $\mathrm{AD}$ affected children (Table 2). Because the TDT analysis included only informative families and was susceptible to chance factors, haplotype TDT was performed. The haplo-

Table 1. Primers for amplification of interferon regulatory factor 2 (IRF2) gene polymorphisms

\begin{tabular}{llllll}
\hline Region & Polymorphism & Primer sequence $\left(5^{\prime}\right.$ to 3') & $\begin{array}{l}\text { Annealing } \\
\text { temp. }\end{array}$ & $\begin{array}{l}\text { Expected } \\
\text { product size }\end{array}$ & $\begin{array}{l}\text { Diagnostic } \\
\text { restriction enzyme }\end{array}$ \\
\hline Promoter & {$[-829 \mathrm{C} / \mathrm{T},-830 \mathrm{C} / \mathrm{T}]$} & $\begin{array}{l}\text { AAGGGTGACCAGCCAGTGAG } \\
\text { GCGCTCCGCTCCATTTAGGA }\end{array}$ & $60^{\circ} \mathrm{C}$ & $245 \mathrm{bp}$ & Fnu4HI \\
Promoter & $-684 \mathrm{C} / \mathrm{T}$ & $\begin{array}{l}\text { GATGGGCCTCCTTTTCGTTCTA } \\
\text { TGTGACACCGACCACCTCCAAG }\end{array}$ & $55^{\circ} \mathrm{C}$ & $180 \mathrm{bp}$ & $\mathrm{MseI}$ \\
Promoter & $-467 \mathrm{G} / \mathrm{A}$ & $\begin{array}{l}\text { GGTAAGGACGCAAGTAATGC } \\
\text { CAAGCAGCGGCTCGTGAGTC }\end{array}$ & $59^{\circ} \mathrm{C}$ & $316 \mathrm{bp}$ & $\mathrm{NlaIII}$ \\
Exon 9 & $921 \mathrm{G} / \mathrm{A}$ & $\begin{array}{l}\text { GGCTGGTCTCAAACTCCTGA } \\
\text { ACCGGATTGCTCTCCTCTTT }\end{array}$ & $56^{\circ} \mathrm{C}$ & $316 \mathrm{bp}$ & Fnu4HI \\
3'UTR & 1739 (ATCCC)6-8 & $\begin{array}{l}\text { CGGACGAGATAATGTGAACT } \\
\text { TTAAAGCAGTCTGAAAATGG }\end{array}$ & $56^{\circ} \mathrm{C}$ & $334 \mathrm{bp}$ & \\
\hline
\end{tabular}


Fig. 1. Genomic structure and locations of polymorphic sites in the human interferon regulatory factor 2 (IRF2) gene

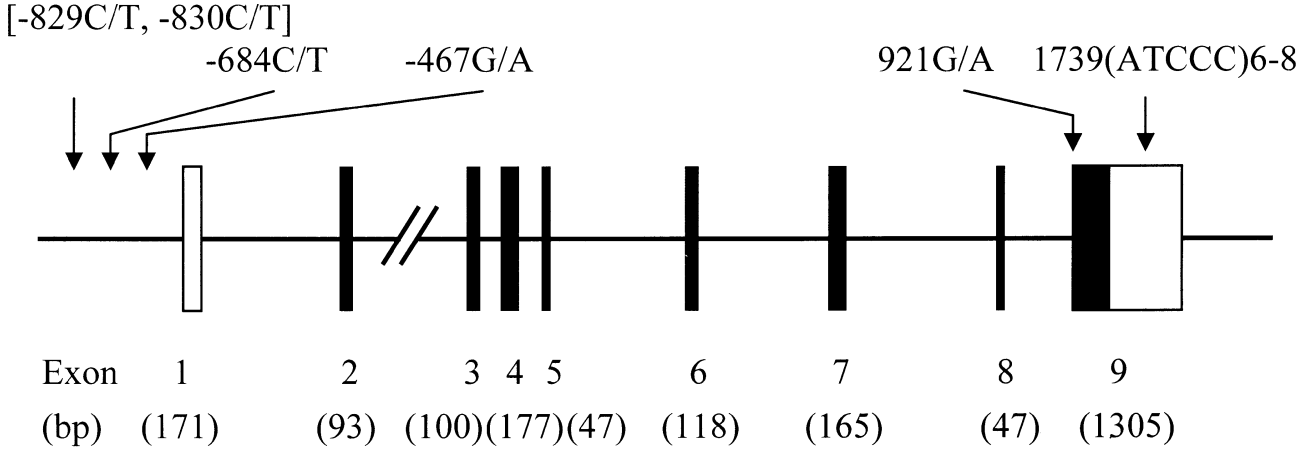

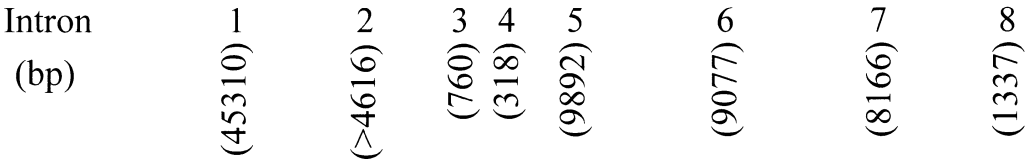

Table 2. Transmission disequilibrium tests for the $I R F 2$ polymorphisms

\begin{tabular}{|c|c|c|c|c|c|c|}
\hline & Allele/haplotype & (Frequency) & Transmitted & Not transmitted & $\chi$-squared & $P$ \\
\hline \multicolumn{7}{|l|}{ Polymorphism } \\
\hline$-467 \mathrm{G} / \mathrm{A}$ & $\mathrm{G}$ allele & $(0.86)$ & 19 & 7 & 5.54 & 0.02 \\
\hline 921G/A & $\mathrm{G}$ allele & $(0.61)$ & 27 & 33 & 0.6 & 0.44 \\
\hline 1739(ATCCC)6-8 & 8 allele & $(0.93)$ & 9 & 10 & 0.05 & 0.82 \\
\hline \multirow[t]{5}{*}{ Haplotype } & GG8 haplotype & $(0.52)$ & 14 & 21 & 1.4 & 0.24 \\
\hline & GA8 haplotype & $(0.28)$ & 23 & 8 & 7.36 & 0.007 \\
\hline & GA6 haplotype & $(0.05)$ & 6 & 6 & 0.08 & 0.78 \\
\hline & AG8 haplotype & (0.09) & 5 & 7 & 0.33 & 0.56 \\
\hline & AA8 haplotype & $(0.06)$ & 1 & 7 & 4.5 & 0.03 \\
\hline
\end{tabular}

type comprising the $-467 \mathrm{G}, 921 \mathrm{~A}$, and 1739 (ATCCC) 8 alleles (haplotype GA8) was transmitted preferentially to AD-affected children $(P=0.007, P c=0.03)$.

In the promoter of $I R F 2$, there are four $\mathrm{Sp}-1$ sites, one NF-kappaB site, and one IRF-1 binding site (Cha and Deisseroth 1994; Harada et al. 1994). The $-467 \mathrm{G} / \mathrm{A}$ polymorphism is not located within these regions. However, TFSEARCH analysis predicted that the polymorphism may lie within the upstream stimulating factor (USF) binding region (http:/www.rwcp.or.jp/papia/). Thus, it is possible that the $-467 \mathrm{G} / \mathrm{A}$ polymorphism affects transcriptional activity of $I R F 2$. On the other hand, the haplotype GA, but not $\mathrm{GG}$, was associated with $\mathrm{AD}$, indicating that the $-467 \mathrm{G} / \mathrm{A}$ polymorphism alone is not likely to be associated with AD. Another possibility is that unidentified mutations that are in linkage disequilibrium with the GA8 haplotype or the haplotype GA8 itself may be associated with AD.

A mouse lacking IRF-2 shows spontaneous development of an inflammatory skin disease involving CD8 $+\mathrm{T}$ cells (Hida et al. 2000). Histopathological analysis of disease tissues in IRF2 knockout mice revealed thickening of the epidermis due to proliferation of keratinocytes in the basal epidermis, similar to the histological changes observed in psoriasis (Hida et al. 2000). Recent genome-wide studies showed loci linked to AD on human chromosomes $3 q 21$ (Lee et al. 2000), 1q21, 17q25, and 20p (Cookson et al. 2001), which are coincident with major psoriasis loci.
Although AD is distinct from psoriasis, both diseases are characterized by dry, scaly skin, disturbed epidermal differentiation, and inflammation that is responsive to $\mathrm{T}$ cellspecific antigens. The data suggest that AD is influenced by susceptibility genes common to psoriasis. Further studies are needed to clarify the role of the IRF2 $-467 \mathrm{G} / \mathrm{A}$ polymorphism in the pathogenesis of AD.

Acknowledgments The authors thank Dr. T. Nogami, Dr. T. Maki, Dr. T. Miyamoto, Dr. S. Nakahara, Dr. N. Imoto, and Dr. T. Kawashima for identification of AD families. This work was supported by a Grantin-Aid for Scientific Research on Priority Areas (C) Medical Genome Science from the Ministry of Education, Science, Sports and Culture of Japan.

\section{References}

Bos J (2000) Immunology of atopic dermatitis. Blackwell, Oxford, pp $178-185$

Cha Y, Deisseroth AB (1994) Human interferon regulatory factor 2 gene. Intron-exon organization and functional analysis of $5^{\prime}-$ flanking region. J Biol Chem 269:5279-5287

Cookson WO, Ubhi B, Lawrence R, Abecasis GR, Walley AJ, Cox HE, Coleman R, Leaves NI, Trembath RC, Moffatt MF, Harper JI (2001) Genetic linkage of childhood atopic dermatitis to psoriasis susceptibility loci. Nat Genet 27:372-373

Hanifin J, Rajka G (1980) Diagnostic features of atopic dermatitis. Acta Derm Venereol Suppl 92:44-47 
Harada H, Fujita T, Miyamoto M, Kimura Y, Maruyama M, Furia A, Miyata T, Taniguchi T (1989) Structurally similar but functionally distinct factors, IRF-1 and IRF-2, bind to the same regulatory elements of IFN and IFN-inducible genes. Cell 58:729739

Harada H, Takahashi E, Itoh S, Harada K, Hori T, Taniguchi T (1994) Structure and regulation of human interferon regulatory factor 1 (IRF-1) and IRF-2 genes: implications for a gene network in the interferon system. Mol Cell Biol 14:1500-1509

Hida S, Ogasawara K, Sato K, Abe M, Takayanagi H, Yokochi T, Sato T, Hirose S, Shirai T, Taki S, Taniguchi T (2000) CD8(+) T cellmediated skin disease in mice lacking IRF-2, the transcriptional attenuator of interferon-alpha/beta signaling. Immunity 13:643655

Juhlin L, Johansson GO, Bennich H, Hogman C, Thyresson N (1969) Immunoglobulin $\mathrm{E}$ in dermatoses. Levels in atopic dermatitis and urticaria. Arch Dermatol 100:12-16
Larsen FS, Holm NV, Henningsen K (1986) Atopic dermatitis. A genetic-epidemiologic study in a population-based twin sample. J Am Acad Dermatol 15:487-494

Lee YA, Wahn U, Kehrt R, Tarani L, Businco L, Gustafsson D, Andersson F, Oranje AP, Wolkertstorfer A, van Berg A, Hoffmann U, Kuster W, Wienker T, Ruschendorf F, Reis A (2000) A major susceptibility locus for atopic dermatitis maps to chromosome $3 \mathrm{q} 21$. Nat Genet 26:470-473

Lohoff M, Duncan GS, Ferrick D, Mittrucker HW, Bischof S, Prechtl S, Rollinghoff M, Schmitt E, Pahl A, Mak TW (2000) Deficiency in the transcription factor interferon regulatory factor (IRF)-2 leads to severely compromised development of natural killer and $\mathrm{T}$ helper type 1 cells. J Exp Med 192:325-336

McElligott DL, Phillips JA, Stillman CA, Koch RJ, Mosier DE, Hobbs MV (1997) CD4+ T cells from IRF-1-deficient mice exhibit altered patterns of cytokine expression and cell subset homeostasis. J Immunol 159:4180-4186 